\title{
A Review and Recommendations for Promoting Environmentally-Friendly Agriculture in Korea
}

\author{
Chang-Gil Kim ${ }^{1}$ and Song Soo Lim $^{2}$ \\ 1. The Korea Rural Economic Institute, Naju 58321, Korea \\ 2. Department of Food \& Resource Economics, College of Life Sciences and Biotechnology, Korea University, Seoul 02841, Korea
}

\begin{abstract}
The objective of this study was to provide a macroscopic evaluation review of environmentally-friendly agriculture (EFA) status and then suggest policy recommendations for promoting EFA in Korea. Amid considerable challenges, including food security, many small-scale farms with increasingly aged farm population and growing competition, agri-environmental indicators (AEIs) and EFA certificate performance shed light on the fact that the trend of the state of the environment reversed, albeit with room to improve. Identifying positive contributions to EFA made by target-oriented long-term EFA plans and the direct payment scheme, this paper suggests to enrich the agricultural information systems, a system approach to agri-environmental resource management, and make a transition toward the low inputs farming systems.
\end{abstract}

Key words: Environmentally-friendly agriculture, agri-environmental indicators, nutrient balance, direct payments, low inputs farming system, best management practice.

\section{Introduction}

Korea is a country that has achieved relatively high GDP per capita and dynamic economic development in a relatively short period. The country faces, however, land scarcity with high population density, where arable land per capital amounts to only 0.03 ha, which are far lower than the world average (0.12 ha) in 2014 [1]. Small family farms with 1.5 ha of agricultural land comprise the dominant stratum. The share of agriculture in domestic GDP has been steadily declining to $2.3 \%$ in 2015 , while agricultural share in employment is 5.2\% [1]. This makes the country one of the largest net agricultural importers in the world with only 24\% of grain self-sufficiency in 2014.

Growing food security challenges have tempted the farm sectors and the government to pursue an intensive "high input-high output (HIHO)" farming system. The HIHO farming system is also attributable to the greater demand for fresh fruit and vegetables, meats, and dairy products from increasing affluent

Corresponding author: Song Soo Lim, professor, research fields: agro-food trade and development. consumers in the country. The use of too much chemical fertilizers and pesticides in tandem with promotion of intensive livestock production has lead to enormous environmental consequences, including the pollution of water quality and soil deterioration. Land-based agricultural activities are identified as important non-point source (NPS) pollutants [2, 3]. Drainage water from paddy fields in Korea is also known to pollute water resources with the suspended solids and nutrients [4].

Against the backdrop of mounting environmental pressures, the Environmentally-Friendly Agriculture (EFA) Fosterage Act of 1997 was enacted to promote sustainable agriculture and environmentally-friendly agricultural practices [5]. This act defines EFA as an industry that minimizes or restricts the use of various chemical substances while conserving and protecting the ecosystems and the environment. The government introduced a direct payment scheme to buttress the EFA in 1999.

At the same time, a rapid spread of environment and health consciousness weighed strongly with the society and consumers. Studies identified many 
important factors that influence the attitude of consumers, such as ethical commitment, safety, knowledge, education and availability [6, 7]. Some of Korean cases reveal that psychographic factors are more useful than sociodemographic factors in explaining purchase of EFA products [8-10].

Despite Korea's substantial development and relevant policy shifts toward EFA, there is little literature diagnosing its status, progress, challenges and desirable future pathways in a comprehensive manner. Thus, this paper aimed to provide a macroscopic evaluation review of EFA status and policy recommendations for promoting EFA in Korea. Close attention was paid to the development of EFA certificate performance, agri-environmental indicators (AEIs) and direct payment schemes, on the basis of which a set of policy recommendations were presented.

\section{An Evaluation Review of EFA}

Since the 1990s, EFA has gained legitimate justification and public support through various policy measures. Table 1 showed a boon and bust pattern for EFA certification performance. With the rapid increase in EFA, organic and non-pesticide cultivated areas reached a peak of 127,100 ha in 2012. The annual growth rate between 2000 and 2012 is averaged at around $48 \%$. The figures of certified farms and marketed volumes are also impressive with $43 \%$ and $37 \%$, respectively.
However, EFA certificate performance turned into a downturned thereafter. Organic and pesticide-free agricultural areas dropped to 79,500 ha and the marketed EFA volumes amounted to a half of the peak quantity in 2016. Brakes being put on the expected EFA proliferation are largely due to two factors [11, 12]. One is a repetitively reported incidence of poor EFA management that results in waning confidence in the market. The other stems from the new 2013 EFA Act that strengthened the rules on EFA certificate requirements. But it is worth noting that EFA indicators have turned around again and are rising between 2015 and 2016.

The National Agricultural Products Quality Management Service (NAPQM) completed the handover of the EFA certificate tasks by June 2017. Now about 66 private institutions are in charge of the whole EFA process, including document examination, on-site examination, approval and post monitoring. It takes about $50 \mathrm{~d}$ from EFA application to a final approval. Labels for EFA products consist of organic agricultural and livestock products, organic processed food, organic feed, non-pesticide agricultural products and non-antibiotic livestock products.

The value of EFA products market in Korea is estimated at about $\$ 1.4$ billion in 2016. Grains hold the largest share of the market at $40 \%$, followed by vegetables (25\%) and specialty crops (20\%). There are good prospects for growth in the EFA market. A trend

Table 1 Evolution of EFA certification farms, areas and production.

\begin{tabular}{lllllll}
\hline \multirow{2}{*}{ Type of farms } & Classification & \multirow{2}{*}{2000} & 2012 & \multirow{2}{*}{2016} & \multicolumn{2}{c}{ Annual growth (\%) } \\
\cline { 5 - 7 } & & & & $2000-2012$ & $2012-2015$ \\
\multirow{2}{*}{ Organic } & No. of farms & 353 & 16,700 & 12,900 & 37.9 & -8.7 \\
& Area (ha) & 296 & 25,500 & 19,900 & 45.0 & -8.1 \\
& Marketed volume (ton) & 6,538 & 168,300 & 110,100 & 31.1 & -13.4 \\
\multirow{2}{*}{ Pesticide-free } & No. of farms & 1,060 & 90,200 & 49,100 & 44.8 & -14.4 \\
& Area (ha) & 876 & 101,600 & 59,600 & 48.6 & -13.5 \\
\hline \multirow{2}{*}{ Total } & Marketed volume (ton) & 15,694 & 841,500 & 461,200 & 39.4 & -18.8 \\
& No. of farms & 2,448 & 107,000 & 61,900 & 43.4 & -13.5 \\
& Area (ha) & 2,039 & 127,100 & 79,500 & 47.8 & -12.3 \\
\hline
\end{tabular}

Source: Seong and Lee, 2017 [11]. 
estimate indicates $\$ 2.3$ billion by 2025 . Non-pesticide products are forecasted to continue, accounting for a dominance share with $77 \%$.

The relative positions of EFA in Korea can be more directly measured by AEIs. Since 1993, AEIs developed by Organization for Economic Co-operation and Development (OECD) have provided a tool to explain the linkages between policies, agricultural driving forces and the state and impact of agriculture on the environment and human welfare [13]. The AEI set is comprised of six themes (soil, water, air, biodiversity, farm management and agricultural inputs), 16 indicators and 37 indicator definitions [14, 15].

Among the list of indicator set, nutrient balance has been widely used to describe and compare the environmental state in agriculture across countries [16]. The indicator values are computed by comparing nutrient inputs and outputs in agricultural production. Fig. 1 explains Korea's nutrient balance in 2013. The total nutrients that entered into agricultural land are 350,000 tons of chemical fertilizers and 190,000 tons of livestock manure. When absorbed nutrients by crops are subtracted, the remaining 230,000 tons could be considered as presenting excess nutrients.

The excess nutrient balance indicates Korea is one of the world's most nutrient-intensive agricultural systems. Korea's nitrogen balance of $169 \mathrm{~kg} / \mathrm{ha}$ in 2012 held the second rank after Luxembourg's 171 $\mathrm{kg} / \mathrm{ha}$. Other OECD countries that report more than $100 \mathrm{~kg} / \mathrm{ha}$ in nitrogen use are Netherlands, Belgium, Israel and Poland [17]. Compared to the OECD average of $24 \mathrm{~kg} / \mathrm{ha}$, Korea has definitely much room to improve the nitrogen intensity. An important factor that contributed to Korea's high nutrient balance was

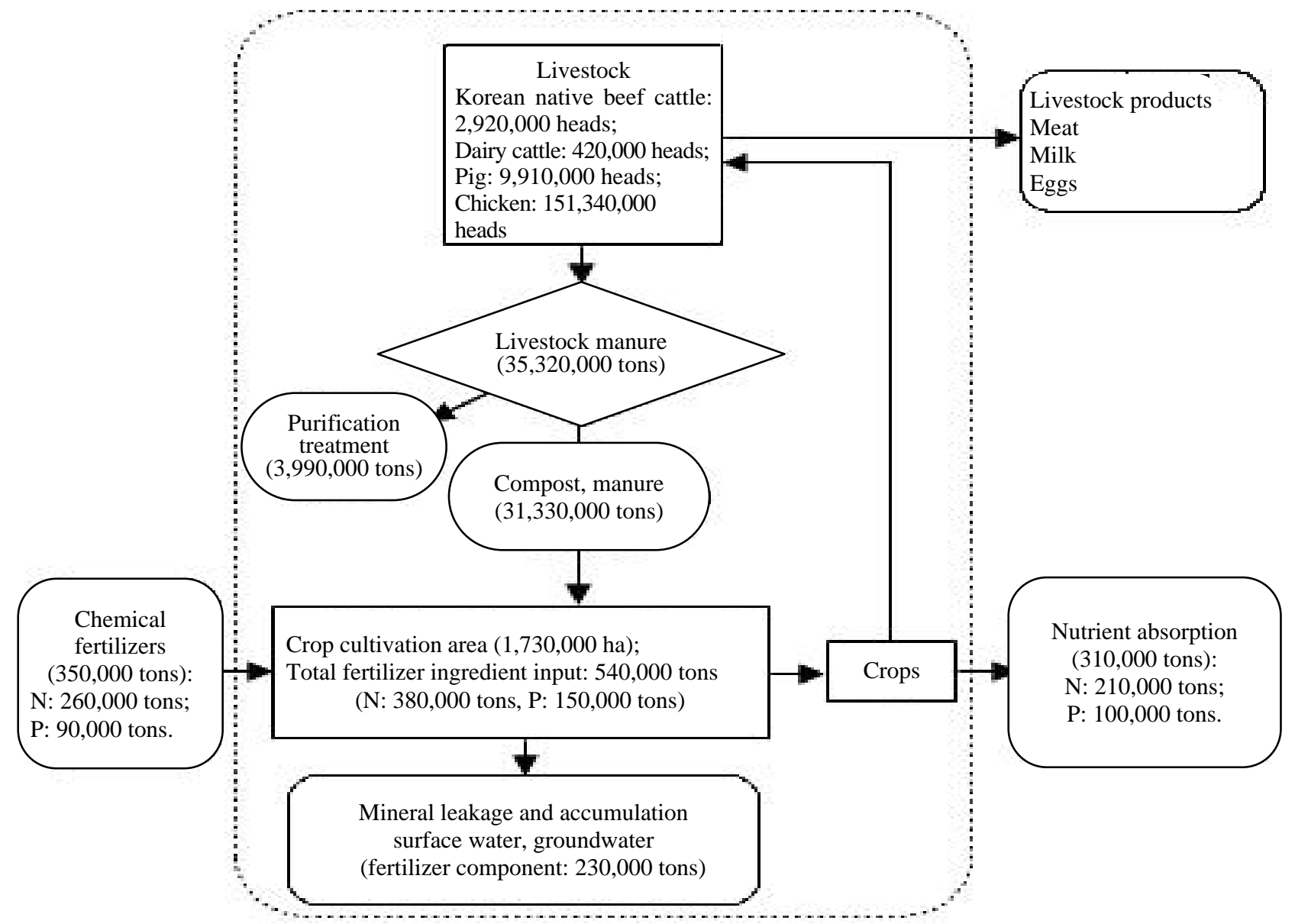

Fig. 1 Computed nutrient balance of arable land in Korea, 2013.

Source: Kim et al. [18]. 
the introduction of new high yielding breeds under the aforementioned HIHO paradigm. Thanks to placing a greater focus on EFA with sustainable farming practices and policy reforms to discourage excessive use of chemical fertilizers, Korea has been able to curb the trend since the mid-2000s.

\section{The Evolution of Agricultural Policies for Promoting EFA}

The OECD and the United Nations suggested that the driving forces-state-response (DSR) model should help understand the complex agri-environmental linkages and feedbacks [19-22]. Following the DSR model, agricultural policy can be seen as a driving force variable that causes changes in environmental conditions, a state variable that has effect on the environmental conditions, and a response variable that triggers responses in the state of the environment.

Not only with the model-based justification but with a requirement of the EFA Act, the Korean government formulates national and regional plans for the development of EFA every five years. Since the first five-year (2001-2005) promotion plan for EFA, each plan has manifested policy goals and basic directions that support specific targeted activities and performance. Table 2 summarized some of key EFA policy projects and their targets.

The 4th fiver-year (2016-2020) promotion plan for EFA lays out ambitious goals and targets to achieve [23]. The EFA plan includes various support and promotion measures, addressing certifying procedures, great-sphere marketing organizations situated in production regions, marketing diversification, production base expansion, provision of organic materials and introduction of self-help funds.

The plan also indicates that steps have been taken to improve the direct payment scheme for EFA farms. As shown in Table 3, the direct payment rates for EFA farms had been steadily increased since its inception in 1999. In 2017, organic farms get up to 1.2 million Korean won (approximately \$1,069) per ha. Time limits for payment are three years for non-pesticide farms and five years for organic farms. But organic farms can earn 300,000 won (paddy fields) or 600,000 won (upland) per ha for additional three years. Area ceilings are 0.1-5 ha. In addition to an increase in the payment rates, the government is considering whether further classification of farms into upland, paddy fields and fruit farms has some merit [24].

So far, several studies find positive evidence of agri-environmental policy measures in EFA [25-27]. The target-oriented long-term plans have contributed

Table 2 Key EFA policy projects and targets.

\begin{tabular}{ll}
\hline Projects & Specific targets \\
\hline EFA base establishment project & EFA districts and complex establishment; \\
Direct payment scheme & EFA inputs, facilities and infrastructure assistance. \\
Biological insect prevention project & EFA certified farms. \\
& Insect prevention with natural enemies; \\
EFA fertilizer support project & Nine eligible vegetables and fruits. \\
& Organic fertilizers, including fixed press cake, fixed organic and organic \\
& composite fertilizers, and compost; \\
Green manure support project & Soil conditioners, including lime and silicic acid. \\
EFA product distribution and consumption & Fallow land cultivating green manure, including Chinese milk vetch, rye, green \\
project & barley and hairy vetch. \\
Agricultural water quality improvement project & Education of producer and consumer organization; \\
Livestock manure treatment support project & Disposition of sediments in lakes and marshes. \\
\hline
\end{tabular}

Source: compiled by authors. 
Table 3 Evolution of the direct payment schemes for EFA farms.

\begin{tabular}{llllll}
\hline \multirow{2}{*}{ Classification } & \multicolumn{5}{c}{ Payment rates $\left(\times 10^{3}\right.$ won/ha) } \\
\cline { 2 - 6 } & Certified farms & $1999-2002$ & $2003-2005$ & $2006-2011$ & 2012 -current \\
\hline \multirow{3}{*}{ Upland } & Low pesticide & & 524 & 524 & 524 \\
& Non pesticide & 524 & 674 & 674 & 1,000 \\
& Organic & & 794 & 794 & 1,200 \\
\hline \multirow{3}{*}{ Paddy fields } & & & & 217 & 217 \\
& Low pesticide & & - & 307 & 400 \\
& Non pesticide & - & 150 & 392 & 600 \\
\hline
\end{tabular}

${ }^{1}$ Low pesticide certification was completely abolished in 2016; ${ }^{2}$ Rice paddy fields are also eligible for rice direct payments. Source: National Assembly Budget Office [28].

to the promotion of EFA and perseveration of the agricultural ecosystem. Nevertheless, greater policy attention should be paid to reduce high surplus levels of nitrogen and other agricultural input use intensity in production [29]. It is also important to strike a balance between providing financial incentives through direct payments that affect farmers' behavior and ensuring the polluter-pays principle that internalizes negative externalities arising from excessive production beyond absorptive capacities of the environment. To build the sustainable EFA system, the government and the agricultural sectors must continue to strive to earn consumers' trust and confidence.

\section{Challenges Ahead and Policy Recommendations for EFA}

The vulnerable state of the environment and limited agri-environmental policy measures shed light on considerable challenges ahead in finding sustainable strategies for the EFA system. A good starting step must be figuring out how to make the best of the existing agri-environment resources. Against a background of current situations, the present study attempts to contribute to the literature suggesting policy recommendations for the use of agri-environment resources in Korea.

First, the agri-environmental information system must be operated at the highest level of efficiency and effectiveness. As seen from the development of AEIs, evidence-based information and knowledge about the DSR variables are crucial to enhance farmers' understanding about the complex agricultural ecosystem and make them strategically interact with market and policy signals. The information system can help policy makers monitor and assess the environmental state and then draw effective policy measures that diminish the source of pollution or augment public services.

A good example is the Agricultural Soil Information System (ASIS, http://soil.rda.go.kr) that provides soil characteristics, crop productivity and climate conditions (Fig. 2). Established in 2011, the ASIS portal covers comprehensive information for 64 crops and presents detailed digital soil maps at a scale of 1:5,000. Since 2016, the ASIS users and farmers have been able to receive fertilizer recommendations on their agricultural land through mobile phones. More importantly, the ASIS enables the adaptation of digital soil maps for precision agriculture and smart farms [30].

There are other information systems as well. The Livestock Manure Information System (LMIS, http://www.nias.go.kr/envi/main.nias) provides technology information regarding compost and liquefied fertilizers. The Rural Agricultural Water Resource Information System (RAWRIS, https://rawris.ekr.or.kr/main.do) is an integrated management system for agriculture base facilities, natural disaster information and agricultural water resources. The Environmental Valuation Information System (EVIS, http://evis.kei.re.kr/index.jsp) is a database upon which the public and stakeholders can undertake various policy analysis, including environmental impact assessment, cost-benefit analysis 


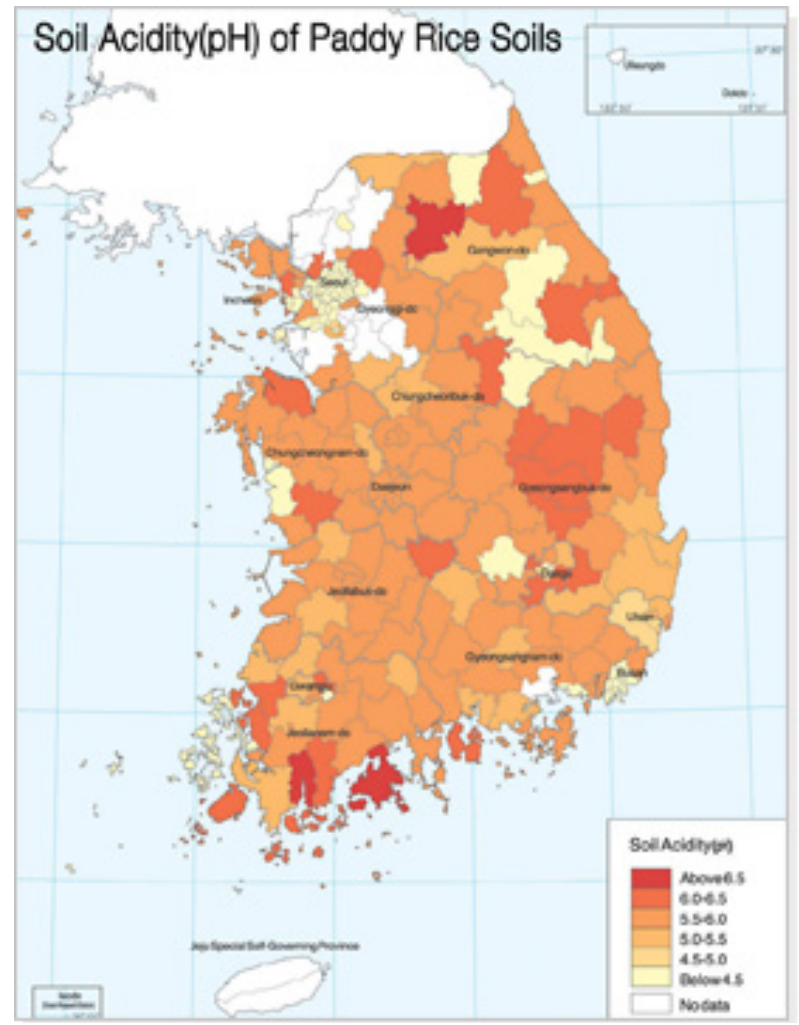

Fig. 2 An example of ASIS in Korea.

Source: ASIS (http://soil.rda.go.kr).

and project feasibility assessment.

Since effective agricultural information systems depend on their availability, access and utilization, sustained investment needs to keep up with new technology and infrastructure development. One of them would be the establishment of platform-independent one-stop service that provides all integrated information about earth resources, that is, agricultural land and soil for stakeholders.

Second, national policies should pursue a system approach to agri-environmental resource management. Inherent links among soil, water and atmospheric resources require system-level approaches to analyze agricultural production practices and make management decisions. The so-called best management practices (BMP) with respect to soil quality conservation, nutrient and water use efficiencies, erosion and runoff prevention, agri-environmental measures and the public education need to be dealt with through the systems. For

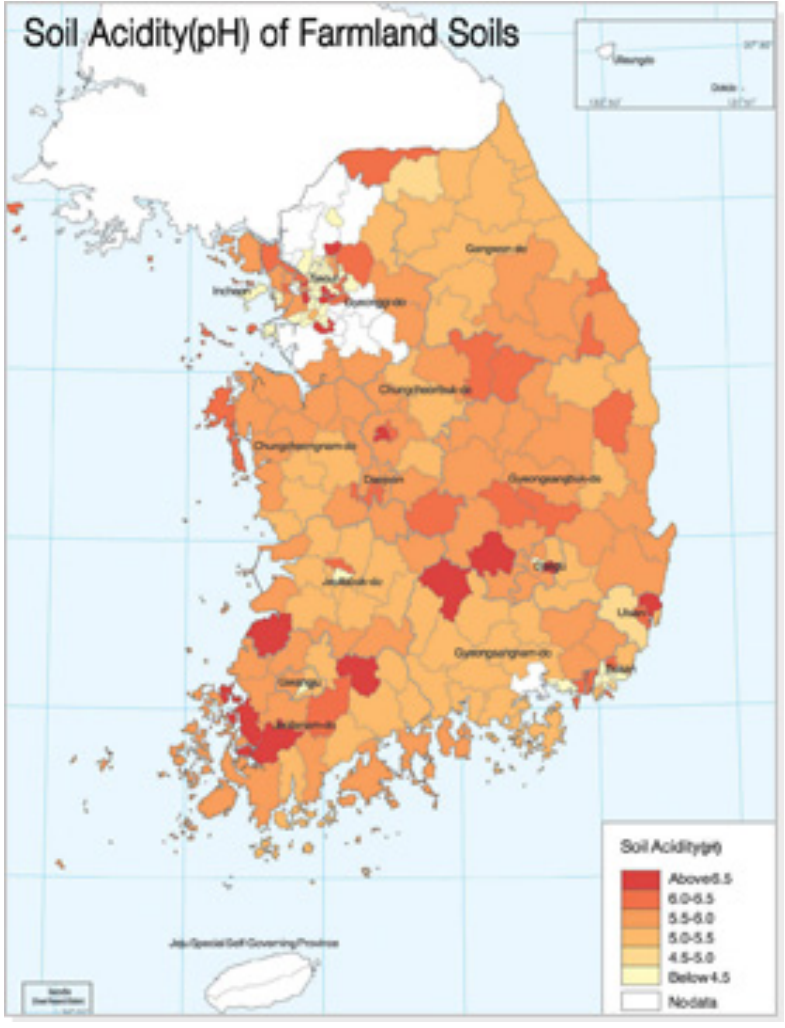

effective carbon emission reductions, the certified emission reduction (CER) plan must be interlocked with other programs, including fertilizer and green manure use, rice production control and bio-energy crop production.

To enable the system approach, all stakeholders, including farmers, farm organizations, central and local governments, and the public should build partnerships and exert concerted efforts to take advantage of the DSR models and AEIs. Taking into the account the aging farm population in rural Korea, the country must prioritize comprehensive capacity building for the BMP. In addition to cutting-edge systematic infrastructure and information, human capital development must be provided by proper trainings and educations. Increased formation of policies regarding knowledge creation and information dissemination is a must, too.

Finally, while developing competitive commercial farms, Korea may approach to EFA in terms of the 
so-called low inputs faming systems (LIFS) that suits for its own situations [31]. As an umbrella concept, LIFS accommodates EFA goals. Against a farming structure where small-scale family farms face ever declining terms of trade and aged farmers account for a growing share in population, Korean agriculture needs to find an ecologically sound, economically viable and socially just farming system. Opportunities behind LIFS arise from the principle and practices of diversity with the highest efficiency of on-farm resources. LIFS will vary spatially and temporally, albeit with certain characteristics of polycultures, the circular economy, organic farming, social farming, biological control, adaptation to climate, as well as the BMP.

As seen from the European Union's agri-environmental measures under the Common Agricultural Policy (CAP), government commitments and long-term plans will play an important role in reducing farmers' overall risk and increasing farm profitability. Any susceptibility of consumers and the society for agriculture's ecological and food safety functions must be relieved by providing trusted information and monitoring and evaluation services. It is because consumers' awareness and support is a pillar of strength for LIFS.

\section{Conclusions}

Increasing competition and commercialization has driven the agriculture sectors toward more intensive farming while stifled the ecosystem. Adoption of the high input-high output farming system with help from technological progress became a norm for modern agriculture and brought up consequential threats and risk to the environment. Against this backdrop, the development of environmentally-friendly agriculture is considered as one remedy for such negative externalities not being taken into account when pursuing agricultural production growth.

The reviewed AEIs and EFA certified farm statistics shed light on the fact that the trend of the state of the environment reversed, albeit with room to improve. Law-based and target-oriented long-term EFA plans have contributed to ensuring stakeholders' confidence and trust in agri-environmental measures and obtaining positive reactions from the market. In particular, studies find that the direct payment scheme for EFA farms help promote EFA practices and management by the beneficiary farmers.

Amid its limited success so far, a mounting concern is how to meet colossal challenges emerged from the declining terms of trade to most small-scale family farms with an increasingly aged population in rural Korea. This paper suggests that each stakeholder should exert considerable influence within the DSR model. Farmers need to build their capacity in order to fully accommodate various agri-environmental resources such as enriched information and knowledge, new technology and infrastructure, and spatial and temporal dynamics of ecological conditions. The government should facilitate a smooth transition from HIHO to the LIFS by providing sustained investment and proper policy signals. The society and consumers should also play a role to fill the potential gap between ecological requirements and farming profitability.

\section{Acknowledgments}

This research was partly supported by Korea University Research Grant.

\section{References}

[1] Korea Ministry of Agriculture, Food and Rural Affairs. 2016. Major Statistics on Agriculture, Forestry, Livestock and Food in 2016.

[2] Novotny, V. 2003. Water Quality: Diffuse Pollution and Watershed Management, 2nd ed.. Boston, USA: John Wiley \& Sons.

[3] Viessman, W., and Hammer, M. 1993. Water Supply and Pollution Control. New York, USA: Harper Collins.

[4] Cho, M., Jang, T., Jang, J., and Yoon, C. 2016. "Development of Agricultural Non-point Source Pollution Reduction Measures in Korea." Irrigation and Drainage 65: 94-101.

[5] Kim, C. G., Oh, S. I., and Kim, T. Y. 2003. Evaluation of 
Eco-friendly Agriculture and Livestock Industry Fostering Policy and Direction of Its Development. Research Report C2003-4, Korea Rural Economic Institute, Seoul.

[6] Rana, J., and Paul, J. 2017. "Consumer Behavior and Purchase Intention for Organic Food: A Review and Research Agenda.” Journal of Retailing and Consumer Service 38: 157-65.

[7] Aschemann-Witzel, J., and Zielke, S. 2017. “Can’t Buy Me Green? A Review of Consumer Perceptions of and Behavior toward the Price of Organic Food.” Journal of Consumer Affairs 51 (1): 211-51.

[8] Kim, S. S. 2007. “A Study on Consumer's Attitude for Food Safety and Purchase of Environment Friendly Agricultural Products.” Journal of Korean Management Association 25 (6): 15-32.

[9] Huh, E. J., and Kim, J. W. 2010. “Consumer Knowledge and Attitude to Spending on Environment-Friendly Agricultural Products.” Korean Journal of Human Ecology 19 (5): 883-96.

[10] Jin, H. J., and Keum, S. H. 2011. "The Effects of Price on Consumers' Purchasing Behavior for Eco-friendly Foods.” Journal of Distribution Research 16 (3): 105-33.

[11] Seong, J. H., and Lee, H. J. 2017. Status and Prospects for Environmentally-Friendly Agricultural Production in 2017. Current Issues No. 39, Korea Rural Economic Institute, Naju, Korea.

[12] Jeong, H. G., Lee, H. J., and Kim, C. G. 2017. Status and Prospects for Environmentally-Friendly Agricultural Production in 2016. Agricultural Policy Focus No. 131, Korea Rural Economic Institute, Naju, Korea.

[13] OECD. 2013. OECD Compendium of Agri-environmental Indicators. Paris: OECD.

[14] Kim, C. G., Ju, H. J., Kim, T. Y., and Lee, S. G. 2008. Policy Connectivity Analysis and Evaluation Using Agri-environmental Indicators. Research Report C2008-57, Korea Rural Economic Institute, Seoul, Korea.

[15] OECD. 2008. Environmental Performance of Agriculture in OECD Countries Since 1990. Paris: OECD.

[16] Parris, K. 1998. "Agricultural Nutrient Balances as Agri-environmental Indicators: An OECD Perspective.” Environmental Pollution 102: 219-25.

[17] OECD. 2015. Environment at a Glance: OECD Indicators. Paris: OECD.

[18] Kim, C. G., Jeong, H. K., Jang, J. G., and Kim, T. H. 2010. Status and Prospects for Environmentally-Friendly Agricultural Production in 2010. Policy Research Report P136, Korea Rural Economic Institute, Seoul, Korea.
[19] European Environment Agency. 1999. Environmental Indicators: Typology and Overview. Technical Report No. 25/1999, Brussels.

[20] OECD. 1999. Environmental Indicators for Agriculture: Concepts and Framework. Paris: OECD.

[21] United Nations. 1995. Information for Decision-Making and Earthwatch. Commission on Sustainable Development E/CN.17/1995/7, New York.

[22] Bockstaller, C., Guichard, L., Makowski, D., Aveline, A., Girardin, P., and Plantureux, S. 2009. "Agri-environmental Indicators to Assess Cropping and Farming Systems: A Review." In Sustainable Agriculture, edited by Lichtfouse, E., Navarrete, M., Debaeke, P., Véronique, S., and Alberola, C. Dordrecht: Springer.

[23] Korea Ministry of Agriculture, Food and Rural Affairs. 2016. Press Release about the 4th Five-Year Environmentally-Friendly Agriculture Plan.

[24] Jeong, H. K., Kim, C. G., and Kim, J. J. 2014. Ways to Improve the Environmentally-Friendly Direct Payment Schemes. Research Report C2014-5, Korea Rural Economic Institute, Seoul, Korea.

[25] Kim, M. S., Lee, Y. H., and Kim, B. S. 2016, “An Economic Evaluation on the Direct Payment System for Environment-Friendly Agriculture in Korea Using AGE Model.” Journal of the Korea Academia-Industrial Cooperation Society 17 (10): 39-45.

[26] Kim, H. 2012. "Developing Strategies of the Large-Scale Districts for a Sustainable Environmentally-Friendly Agriculture.” Korean Journal of Organic Agriculture 23 (2): 233-45.

[27] Jung, J. H., and Choi, K. S. 2010. “An Evaluation of the Environment-Friendly Farming Zone Program: A Double-Difference (DD) Analysis.” Journal of Industrial Economics and Business 23 (3): 1141-58.

[28] National Assembly Budget Office. 2014. 2015 Evaluation for Government Performance: The Economy and Industries.

[29] OECD. 2017. Agricultural Policy Monitoring and Evaluation 2017. Paris: OECD.

[30] Söderström, M., Sohlenius, G., Rodhe, L., and Piikki, K. 2016. "Adaptation of Regional Digital Soil Mapping for Precision Agriculture.” Precision Agriculture 17 (5): 588-607.

[31] Biala. K., Jean-Michel Terres, J., Pointereau, P., and Paracchini, M., eds. 2008. Low Input Farming Systems: An Opportunity to Develop Sustainable Agriculture. Ranco, Italy: JRC Summer University. 